\section{CERN staff in pay dispute}

\section{London}

STAFF at CERN, the European particle physics centre in Geneva, are calling for the resignation of their director-general, the Nobel laureate Professor Carlo Rubbia, in a deepening dispute over pay and pensions. Rubbia has been singled out because a pay package he proposed together with the staff association over the summer has been rejected by an advisory committee to CERN's governing council.

CERN staff and Rubbia proposed a 6.4 per cent pay increase in real terms by 1993, but Rubbia says that CERN member states may be unable to commit themselves to pay increases beyond 1991. The CERN council is expected to offer just a 3 per cent increase in the coming year, when it meets on 14 December with no longer-term promises. Dr Henry Atherton, an applied physicist and vicepresident of the staff association, says that CERN has also allowed a debt of some SFr350 million (about $£ 140$ million) to build up in the staff pension fund, by failing to meet contributions which were increased in the early 1980s. Money has been withheld from the fund to pay for CERN's Large Electron-Positron collider, Atherton says.

The call for Rubbia's departure is little more than a posture on the part of the staff association, but CERN staff have also started a work-to-rule. Support staff and a small number of research physicists are refusing to use their own cars on the sprawling CERN site or to work unpaid overtime, and have abandoned the use of CERN's internal electronic communications in favour of handwritten notes. Atherton says that CERN staff will now obey strict safety rules to the letter.

So far, the dispute has not strongly affected scientific output, according to Dr David Miller, a regular user of CERN's facilities from University College London. Others suggest that the squabble is diverting attention from the real problem: the reluctance of members to increase contributions to fund new science.

There are also doubts among CERN's outside users over the validity of the staff pay claim. CERN staff argue that their pay lags behind that in comparable international organizations (such as the European Southern Observatory) and in local Geneva industry. But Professor Don Perkins from the University of Oxford a former chairman of the UK Science and Engineering Research Council's Nuclear Physics Board, says that a better comparison is with outside users, who are mostly paid much less than CERN staff.

Rubbia says that the pensions issue is not an immediate problem, because CERN is legally obliged to meet its contri- butions. Payments have lagged behind the pension fund's total agreed value by 19 per cent, Rubbia says, but this is within the limits allowed by Swiss law.

But CERN member states are unlikely to guarantee pay increases as far forward as 1992-93, because national science budgets are fixed on a yearly basis. Rubbia says that in the absence of an agreed total CERN budget for 1992-93, individual components such as pay increases cannot be guaranteed, but adds that he will resist "very strongly" any attempts to reduce spending on the running costs of CERN experiments. This will simply shift the problem onto member states' domestic science budgets, he says, if CERN's outside users are to continue with the present volume of work. Peter Aldhous red, high-level clouds.

\section{European society seeks a role}

\section{London}

MORE than 600 astronomers have come together to form the European Astronomical Society (EAS), the first Europeanwide professional body in the field. The society will fulfil a useful role if it can provide a forum for the discussion of collaborative European astronomy projects, British astronomers say. Some feel that important collaborations such as the European Southern Observatory could be better coordinated.

Britain already has an analogue to the new society in the Royal Astronomical Society (RAS). But Dr Paul Murdin, from the Royal Greenwich Observatory, says that the new EAS should still attract UK members.

\title{
Hubble spotlight on Saturn's storms
}

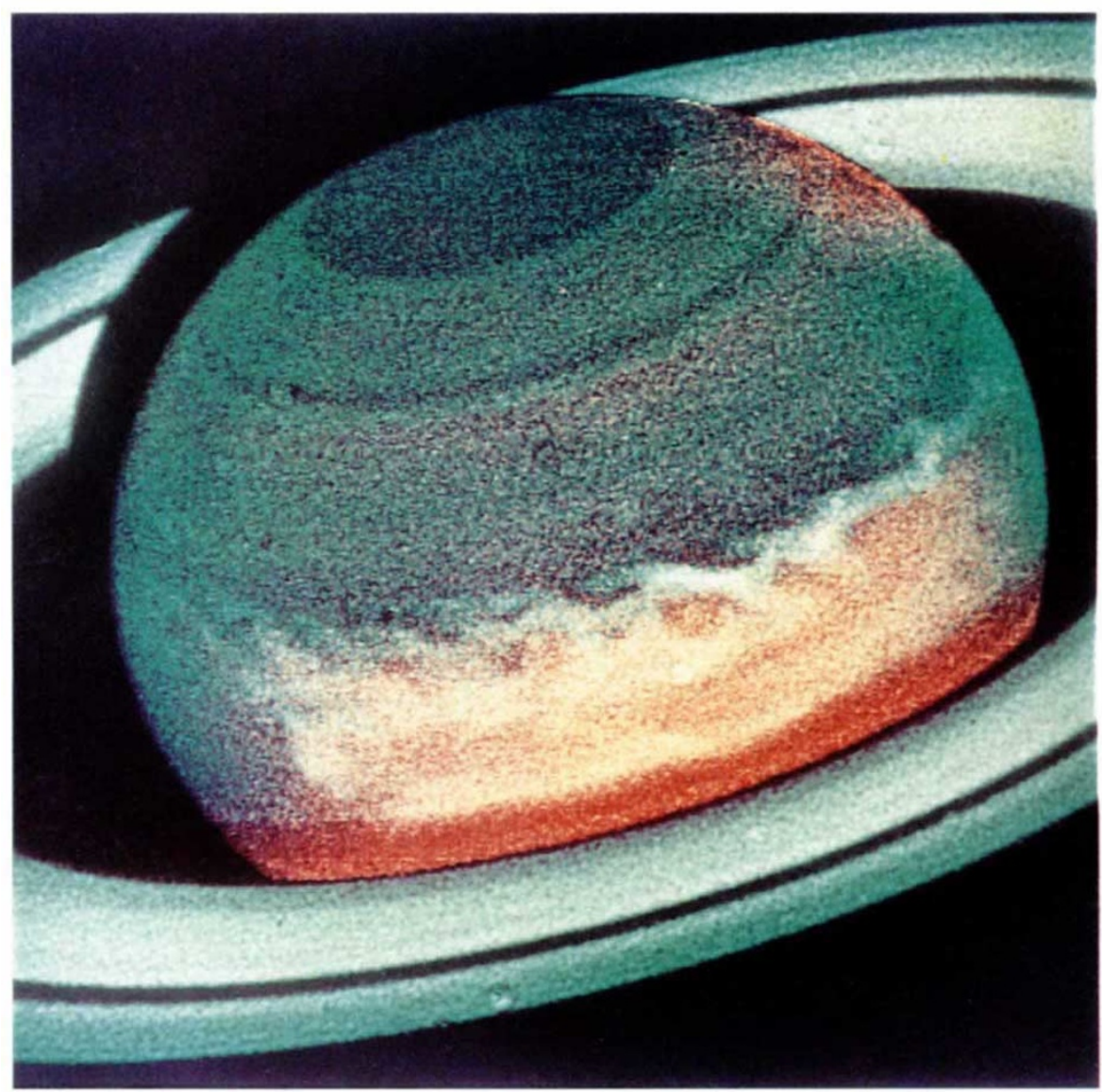

Saturn's Great White Spot, a massive storm in the planet's hydrogen- and helium-rich atmosphere, has astounded astronomers since it first developed two months ago. Almost certainly a result of upwelling traced by ammonia-ice clouds from the lower atmosphere, the spot has grown from $20,000 \mathrm{~km}$ across in early October to encompass much of Saturn's equator now. To learn the most about this nearly unique event (only four such spots have been seen before, in 1876, 1903, 1933 and 1960, all smaller than the present one) NASA turned the planetary camera of the Hubble Space Telescope towards it on 9 November. The high resolution available from the telescope reveals unprecedented detail, showing in particular the evidence of turbulent eddies around Saturn's spot that resemble those around its larger cousin, Jupiter's Great Red Spot, which has lasted at least 400 years continuously. (Blue in the picture indicates low-level clouds; 